\title{
THE PHYSICS OF LEONARDO DA VINCI
}

\author{
Nota del m.e. FERDINANDO BORSA (*)
}

(Adunanza del 2 maggio 2019)

SunTO. - Tra le numerosissime attività di Leonardo da Vinci ci sono molti esempi in cui il grande artista si confronta con fenomeni fisici di cui cerca di trovare una spiegazione. Tuttavia lo studio delle leggi della fisica da parte di Leonardo non sembra motivato dal'interesse verso la fisica in se ma in quanto la spiegazione di fenomeni fisici gli risulta importante nella sua attività di artista, ingegnere e osservatore della natura. E' sorprendente che il grande genio abbia enunciato in modo magistrale il paradigma della scienza moderna di Galileo e Newton. In questa nota, dopo aver accennato ad alcune grandi intuizioni di Leonardo fisico si cerca di verificare in quale misura Leonardo abbia applicato la metodologia scientifica cosi ben annunciata allo studio di leggi della fisica. Tra i vari argomenti trattati nella sterminata produzione Leonardesca si è scelto di analizzare gli studi sull'attrito e sulla idrodinamica argomenti sui quali Leonardo si è impegnato con maggior continuità e sistematicità.

$$
* * *
$$

ABSTRACT. - Among the many extraordinary activities of Leonardo da Vinci there are a few examples when he confronts himself with physical phenomena that he tries to explain. However, the studies of physical laws by Leonardo does not seem to be motivated by the interest in Physics itself but rather by the explanation of phenomena entering in his activity of artist, engineer and observer of nature. Nevertheless it is surprising that the renaissance genius is able to enunciate the paradigm of modern experimental science as later established by Galileo and Newton. In the present note, after having reviewed some of the most spectacular intuitions by Leonardo in the field of physics, we try to verify to which extent he applies the scientific methodology, he so well enunciates, to the study of physical laws. Among the very extensive production of Leonardo we chose to analyze in detail the studies on friction and on hydrodynamics since these are the subjects that he pursued with more continuity and method.

(") Istituto Lombardo Accademia di Scienze e Lettere, Milano. Dipartimento di Fisica, Università degli Studi di Pavia, Italy. E-mail: ferdinando.borsa@unipv.it 


\section{INTRODUCTION}

The bibliography of Leonardo da Vinci is huge. Suffice to say that Gerolamo Calvi charged in 1905 by the Istituto Lombardo di Scienze e Lettere to list all references to works on Leonardo reported 1500 items. At least as many were added in subsequent times. Most of the studies and biographies deal with the artistic masterpieces of Leonardo but there is also a large number which deal with Leonardo as a scientist. In this second case most of the interest seems to be focused of the genius of Leonardo in describing nature through careful observation and description by the use of drawings of exceptional quality. This is particularly evident in the works of Leonardo in the field of engineering and anatomy. In the first case he does not really invent any new machine but, for the first time, he uses technical drawing to show how the different parts operate and he often introduces modifications and improvements. Many museums around the world display models of Leonardo's machines which were constructed following the original drawings, some of them work some of them do not. None of them was probably constructed at the time of Leonardo. Furthermore the anatomical drawings are of incredible accuracy and if he had published them with the collaboration of Antonio Della Torre, then professor of anatomy at the University of Pavia, he would have anticipated the atlas of Vesalio by some fifty years.

On these premises most of the biographers and scholars of Leonardo conclude that he was a great scientist besides being one of the greatest artist ever lived. But what about Physics? Physics is not a descriptive science nor is engineering. Physics is an experimental science based on a paradigm which requires experiments from which to arrive by inductive reasoning to the formulation of theories in mathematical language, theories which can in turn be used to explain further experiments and natural phenomena with deductive reasoning. Leonardo did not seem to be interested in developing physical theories by themselves but he was forced to deal with physical laws whenever he pursued his interests in art, engineering and observation of nature. $\mathrm{He}$ studied optics since light is of fundamental importance in painting, he studied fluids as part of his work as hydraulic engineer, he studied mechanics to learn how machines operate, he studied acoustics as a result of his interest in musical instruments and so on. It is amazing to discover that Leonardo had a very clear idea of what is the paradigm of modern science. Let us see what he has to say: 


\begin{abstract}
"Nessuna umana investigazione si può dimandare vera scienza, s'essa non passa per le matematiche dimostrazioni..." ("no human investigation can be considered true science, if it does not go through mathematical demonstrations...")

"Ma prima farò alcuna esperienza, ..., perchè mia intenzione è allegare prima l'esperienza, e poi colla ragione dimostrare, perchè tale esperienza è costretta in tal modo ad operare". ("But first I will perform some experiments ..., because my purpose is to asses first the experience (experiment?) and then with reasoning demonstrate why the experiment is coming out that way")
\end{abstract}

On the basis of the above premises it is natural to ask oneself if Leonardo did indeed use the modern science method to investigate physical phenomena. It is very difficult to address this question because the interest of Leonardo in specific physical phenomena is scattered over space and time. It is scattered in space because Leonardo writings have been largely dismembered and are found now in different museums and institutions around the world organized in the form of Codes and Manuscripts. It is scattered in time because, although the chronology of the "folios" has been reconstructed thanks to the wonderful work of Carlo Pedretti, Leonardo used to work on a given problem only for a short time, then jump to a different subject, may be to an artistic drawing or a technical one or simply to the note of his expenses all superimposed on the same "folio" then go back to the initial subject days or months later on the same or on different "folios". This difficulty in concentrating on a subject, particularly when it had to do with a physics law which requires concentration, method and persistence is part of a recent investigation by Carlo Catani and Paolo Mazzarello (Brain 2019,142,1842-1846) which is based mostly on Leonardo's problem to complete his art projects. The authors arrive to a striking conclusion which will most likely ignite a controversy in years to come.

There are only a few physicists who looked at Leonardo's contribution in the field of Physics. Among them I like to quote here in chronological order: Gilberto Govi (Leonardo letterato e scienziato, Saggio delle opera di Leonardo da Vinci, Ricordi, Milano 1872 pp. 522); Leopold Infeld (Leonardo Da Vinci and the fundamental laws of science, Science and Society, Vol 17, $\mathrm{N}_{0} .1$, Winter 1953 pp. 26-41); Domenico Argentieri and Sebastiano Timpanaro (in Leonardo, edited by Ralph Steadman, Jonathan Cape Ltd, London 1983); Fritjof Capra 
(The science of Leonardo: Inside the mind of the Great genius of the Renaissance, Anchor Books, New York 2007); Luigi Borzacchini, La solitudine di Leonardo. Il genio universale e le origini della scienza moderna. Edizioni Dedalo (2019).

All the above cited works are very captivating and well documented but they are generic on the subject of physics and all seem to miss the point which interests me the most here: did Leonardo apply the paradigm of modern science to his investigations of a particular physical phenomenon to derive a law formulated in mathematical terms ? Only recently this issue has been examined in detail by a Cambridge professor of engineering, Ian M. Hutchings (Leonardo Da Vinci's studies of friction, Wear 360-361 (2016) pp. 51-66). In his paper Hutchings traces all the studies of Leonardo over a span of 20 years dealing with friction and its applications. He demonstrates that Leonardo did extensive experimentation on the subject and that he arrived to the formulation of the correct laws of friction two hundred years before Guillaume Amontons who is credited with the formulation of the laws.

In the present note I would like to discuss first the work of Hutchings to see if Leonardo did indeed perform the experiments that he drew and to which extent he arrived to the mathematical formulation of the laws of friction which actually imply only the understanding of the concept of proportionality of two physical quantities. By using Hutchings' methodology I will try then to analyze the work of Leonardo in the field of hydrodynamics in order to show to which extent he came close to formulate Torricelli 's Theorem, the definition of fluid flow and the principle of continuity. Only in discussing in detail these two specific cases one can get a clear idea of the extent to which Leonardo was able to apply the principles of modern scientific investigation which he had indeed formulated correctly. But first let us see some of the "discoveries" in physics reported by most of the biographers and scholars of Leonardo.

\section{SOME INTUITIONS AND ANTICIPATIONS OF PHYSICS LAWS BY LEONARDO}

The fame and recognition of Leonardo as a physicist is attributed by the many biographers and scholars of the renaissance genius to the many intuitions he had about the explanation of physical phenomena and laws. It is worth mentioning a few of them to see how he came about to his 
almost miraculous anticipations. We could start with the most far-fetched which is mentioned by Infeld in his article. When Leonardo says "prendi un oggetto riscaldato al color rosso e pesalo nuovamente quando è freddo" (take an object heated to the red color and weigh it again when is cold) does he anticipate the ponderability of matter expressed by the famous relation between energy and mass, $\mathrm{E}=\mathrm{mc}^{2}$, result of Einstein's theory of special relativity? Very unlikely! Nevertheless the scientific curiosity of Leonardo and his fine intellect are shown in the mere fact that he poses the right questions. Let us now see some more concrete cases:

\section{a) The explanation of the blue color of the sky}

In the Leicester code Leonardo gives an explanation of the blue color of the sky which is remarkably close to the correct explanation given by Lord Rayleigh in 1871 based of the detailed theory of the scattering of solar light by the molecules in the atmosphere.

"Dico l'azzurro in che si mostra l'aria non essere suo proprio colore, ma è causato da umidità calda, vaporata in minutissimi e insensibili attimi, la quale piglia dopo se la percussione dei razzi solari e............." (I say that the blue which the air shows is not its own color but is caused by the hot humidity, vaporated in tiny and insensitive fractions(?) which receives on itself the percussion of the solar rays and......)

In other folio's Leonardo describes experiments where he shines light on smoke rising in front of a dark background and he obtains so a bluish color of the smoke. Clearly he arrives to the intuition of the explanation of the blue color of the sky by applying analogical reasoning as he does very often in his scientific observations

\section{b) Vibrations, waves and the nature of sound and light}

In the study of wave motion Leonardo shows at his best the quality of subtle observer of nature and of scientific reasoning. He observes the circular waves generated by a stone cast in a pool of water and concludes in the Manuscript A "....e la ragione di questo è che l'acqua, malgrado sembri muoversi, in realtà non lascia la posizione originale, perchè il vuoto creato dal sasso si richiude prontamente. Pertanto il moto prodotto dall'aprirsi e chiudersi veloce dell'acqua ha come conseguenza solo un urto che può essere descritto come un tremore piuttosto che un movimento" ("....and the reason of this is that the water, although it seems to 
move, in reality does not abandon the original position, because the vacuum created by the stone is closed immediately. Therefore the motion generated by the fast opening and closing of the water has the only consequence of an impact which can be better described as a tremor rather than a movement").

This statement may appear trivial to us today but it took 200 years to arrive to a rigorous formulation of transverse waves by Huygens (a colleague of Newton) who used in his Traitè de la lumiere (1690) words that seem to have been copied from Leonardo statement. Leonardo went even further. By using analogical reasoning, so dear to him, he states that light and sound must also be transverse "tremors" although the nature of either was totally unknown to him. This indicates that his mind was more driven by his artistic sense than by sound scientific reasoning.

\section{c) Reflection, refraction and dispersion of light}

In his treatise on painting, where Leonardo gathers most of his studies on light, one can find several examples of his understanding of the law of reflection always expressed by drawings of light rays impinging on a surface and bouncing back forming an angle equal to the incident angle but he never states clearly the law which implies that the two rays and the normal to the surface have to be in the same plane.

Regarding the phenomenon of refraction Leonardo observes correctly that light rays are bent as they cross the surface separating two transparent media but he never investigates the phenomenon quantitatively. Understandably, with the knowledge of mathematics at his time, he could not arrive at the Snell's law.

In the Leicester code Leonardo describes in words the decomposition of white light in different colors when crossing water anticipating the experiments of Newton with the prism:

“........Ma se tu poni tal bicchiere pieno d'acqua sul piano della finestra in modo che dall'opposta parte lo ferischino li razzi solari, allora tu vedrai li predetti colori generarsi nella impressio fatta dalli razzi solari penetrati per esso bicchiere e terminati sopra il pavimento...". (“......But if you set such glass full of water on the plane of the window in such a way that from the opposite side it is hit by the sun's rays, you will see the given colors generated by the impression done by the solar rays penetrated in the glass and terminated on the pavement..." 
As can be seen from the folio reproduced in Fig. 1, in this rare case he formulates the observation of light dispersion correctly in words while the drawing is grossly wrong! Normally is the other way around with Leonardo.

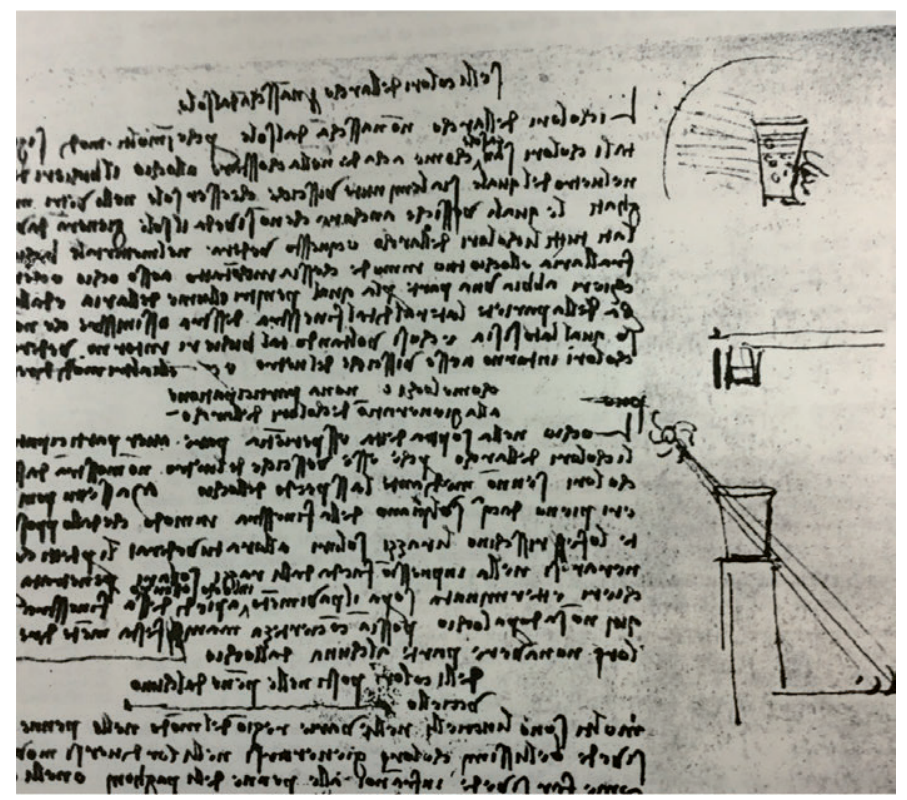

Fig. 1.

\section{d) The three laws of mechanics (Newton's laws)}

Classical mechanics is based on Newton's second law, $\mathbf{F}=\mathrm{m} \mathbf{a}$. At the time of Leonardo calculus did not exist and thus it was impossible for Leonardo to acquire the concept of acceleration. Without acceleration it was impossible to define the force and the inertial mass. In fact Leonardo never mentions mass (he talks about weight but not as a force) and gives a definition of force which is purely metaphysical ! However, the first law or law of inertia, which is a particular case of the second law when $\mathbf{F}=\mathbf{0}$ could be discovered by Galileo who had the great intuition that to investigate the motion of bodies one has to eliminate friction from the picture. Some biographer and scholars of Leonardo claim that he anticipated Galileo by formulating the law of inertia in these terms: 
"Ogni moto naturale e continuo desidera conservare suo corso per la linia del suo principio" "Every natural and continuous motion desires to maintain its course along the line of its beginning"

"Ogni moto attende al suo mantenimento, ovvero: ogni corpo mosso sempre si move, mentre che la impressione della potenzia del suo motore, in lui si riserva" ("Every motion aims at his continuation, namely: every body set in motion keeps moving, as long as the impulse of the power of its motor, remains in it")

It is clear to me that these statements do not adumbrate the law of inertia. In the first one there is no mention of the need for having no force on the object while the second is a formulation of the theory of the impetus of Buridan in line with Aristotelian dynamics.

The third law is another matter. The quasi-static version namely to every action there is a reaction equal and opposite does not require any understanding of motion and thus it is no surprise that Leonardo did arrive to the correct formulation of the third law:

In the folio 135 of the Arundel code we read:

"Ogni corpo si muove in direzione opposta dal punto da cui è spinto dall'oggetto che lo colpisce...Il corpo colpisce l'oggetto nella stessa misura in cui l'oggetto colpisce il corpo" "Every object moves in the opposite direction from the point from which is pushed by the object which strikes it....The body strikes the object in the same way as the object strikes the body"

The more complete formulation namely the conservation of momentum for an isolated system was out of reach for Leonardo. However, it is surprising that he understood and described many cases of collisions both elastic and inelastic in which the conservation of momentum is implicit.

In the Arundel code $263,83 \mathrm{v}$ he reports this remarkable statement which is clearly the result of reasoning on experiments performed

“..ci sono due tipi di percussione, quando l'oggetto si allontana dal corpo in movimento che lo ba colpito e quando un corpo rimbalza contro un oggetto che lo ha colpito..... Quando i due corpi hanno lo stesso volume e peso il corpo che viene colpito lascia il corpo che lo colpisce al suo posto e prosegue con il moto del primo corpo" ("...there are two types of collision, when the object goes away from the moving body that has hit it and when a body bounces back from an object that has hit it... When 
the two bodies have the same volume and same weight the body which is hit leaves the body which hit it at his place and continues with the motion of the first body")

All different cases of collisions are summarized in manuscript $\mathrm{A}$ folio $8 \mathrm{r}$ with beautiful and accurate drawings of the trajectories of the colliding bodies without, however, any description of the experiments which led to those geometrical conclusions.

\section{e) The conservation of energy and the perpetual motion}

Leonardo could not have the concept of work and of energy. He struggles to build a machine which can operate continuously without an energy input. After many attempts he abandons the idea and concludes that it is impossible and he compares whoever tries to obtain perpetual motion to the alchemist:

"O speculatori dello continuo moto, quanti vani disegni, in simile cerca, avete creato! Accompagnatevi colli cercatori dell'oro" "O speculators of continuous motion, how many useless designs, in such a search, you have created! Join the ones who search for gold"

In effect one has to make a distinction between continuous motion and perpetual motion. In the first case the motion can continue indefinitely in a force field which is conservative. The motion of celestial bodies is an example. Thus in principle continuous motion is possible if one can eliminate frictional forces completely. A machine moving continuously in a conservative force field would not generate any work but only measure time. With the discovery of phenomena such as superconductivity and superfluidity a continuous pendulum is in principle feasible. Perpetual motion, on the other hand is impossible even in principle because it violates the principle of conservation of energy. It is not clear if Leonardo was after a machine that would measure time by running continuously without friction or a machine that would produce work without an energy input i.e. perpetual motion. In the first case his statement would be wrong while in the second case it would be correct.

Leonardo expressed, however, the intuition of the conservation of energy when he describes the cycle of a living creature. He says: 
"Il corpo di qualunque cosa, la qual si nutrica, al continuo muore e al continuo rinasce, perché entrare non può nutrimento, se non in quelli lochi, dove il passato nutrimento è spirato......Ma se tu ne rendi tanto quanto se ne distrugge alla giornata, allora tanto rinasce di vita, quanto se ne consuma....." "The body of whatever thing, that nourishes itself, continuously dies and continuously is born again, because no nourishment can enter, if not in those places where the previous nourishment is finished.... But if you give back the same amount that was destroyed, during the day, then so much is born again of life as it is consumed..."

The above statement sounds pretty much as the application of the first principle of thermodynamics to a living creature!

I mentioned some of the most relevant examples of intuitions of Leonardo about physical laws. These have been reported in most of the biographies of the artist and in specific studies about Leonardo as a scientist. As I pointed out along the way there is no systematic study of physics in the above instances, no quantitative experiments, no mathematical formulation of any law. On the basis of those "discoveries" one could claim that Leonardo was the greatest scientific genius and somebody else could claim that he was only a great artist with acute sense of observation and great fantasy (like e.g. the French writers Jules Verne and Albert Robida who anticipated in their novels many discoveries of the following century)! This is why it is necessary to focus on a specific physics law that Leonardo studied over the years with some consistency to understand to which extent he applied the paradigm of modern science that he so clearly stated. We thus report in the following the studies of Leonardo on friction and on fluid dynamics.

\section{THE LAWS OF FRICTION}

I. Hutchings, in his important paper (Wear 360-361 (2016) 51-66), starts by observing that some of the first experiments on the study of friction are drawn on a small notebook- size piece of paper (which I call jokingly "pizzino" i.e. the name of the pieces of paper that the mafia bosses used to communicate with their accomplices from the jail):

Hutchings points out,with maybe excessive animosity, that the art historians who examined the "pizzino" (Fig. 2) were only interested in 
the sketch, on the up right hand corner, of the old woman (Elena of Troy in old age?) and the Petrarca saying "cosa bella mortal passa e non dura" (a mortal beautiful thing does not last).

Starting from this "pizzino" Hutchings goes back and reconstructs all investigations of Leonardo regarding the laws of friction and their applications. These span over a period of about 20 years and they present conclusions often incorrect that were changed later.

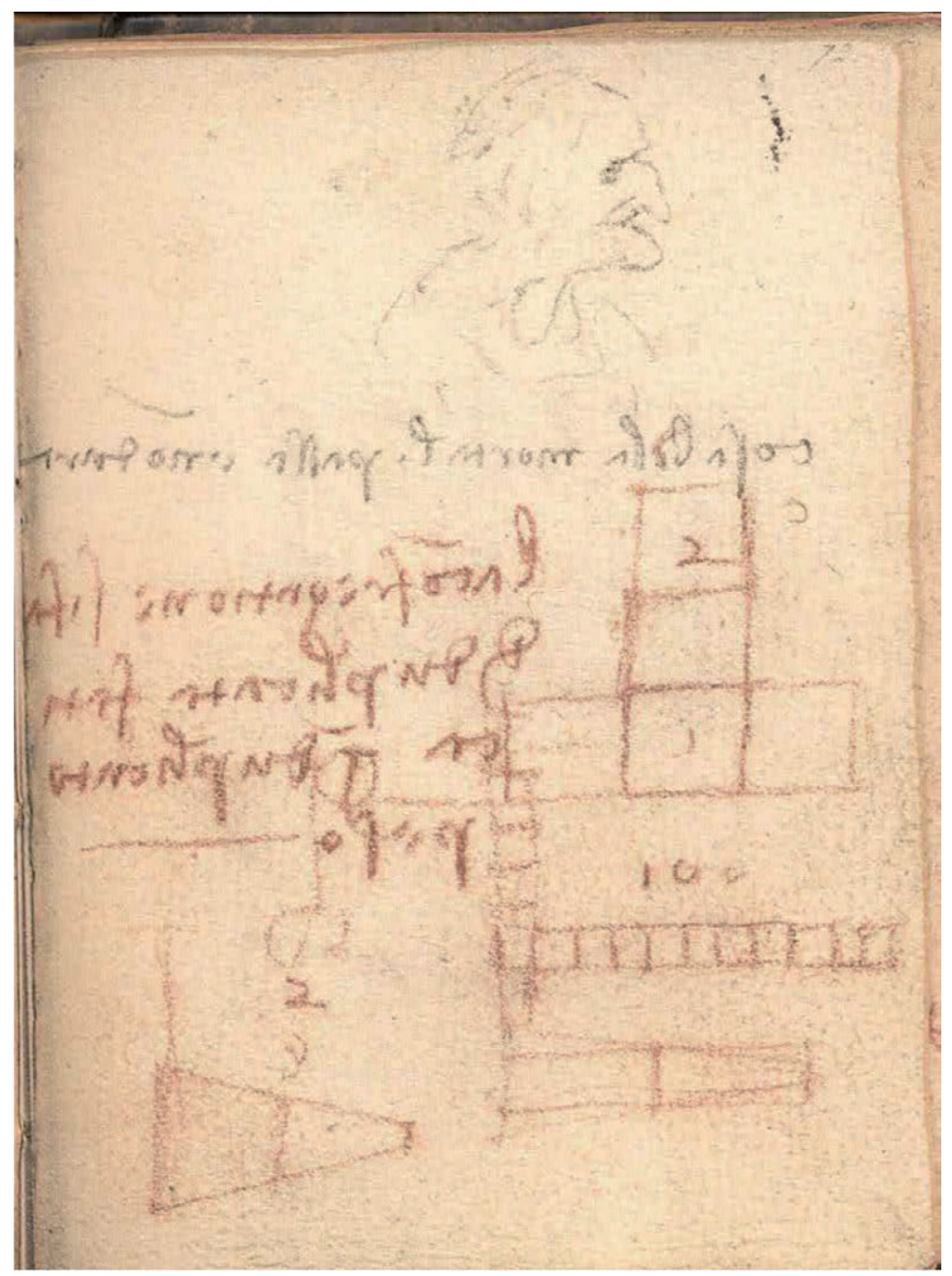

Fig. 2. 
The two drawings reproduced (Figg. 3-4) (two among the many regarding friction found in Leonardo's folio's) represent possible experiments designed at establishing the amount of the frictional force and its dependence upon the weight of the object experiencing friction and the dependence of the frictional force from the surface area of contact of the object on the plane. In the first drawing the many objects are connected to a sort of handle. This seems to indicate that Leonardo tried to measure the frictional force by the effort necessary to set the object in motion. On the folio there is no mention of quantitative results of the experiments. One finds only this comment

"La confragazione si fa in duplicata fatica in duplicato peso" "Friction is done in twice the effort for twice the weight")
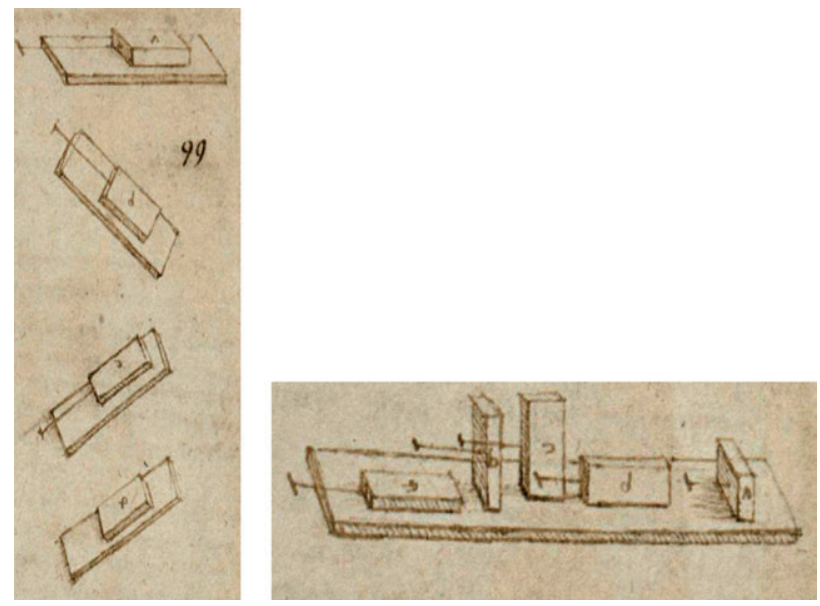

Fig. 3.

The idea is there but there is no attempt to formulate the law in mathematical terms. He does not identify the friction and the muscular force as two equal and opposite forces nor does he distinguish static from dynamic friction. In the second drawing Leonardo sets up a more quantitative experiment. He decides to compare the frictional resistance to the weight acting in opposite direction. But again there are no notes about the results of the experiment. He seems to be content to find out that the same weight displaces the object independently of the area of contact on the plane. Again he is measuring the static friction not the dynamic one. 


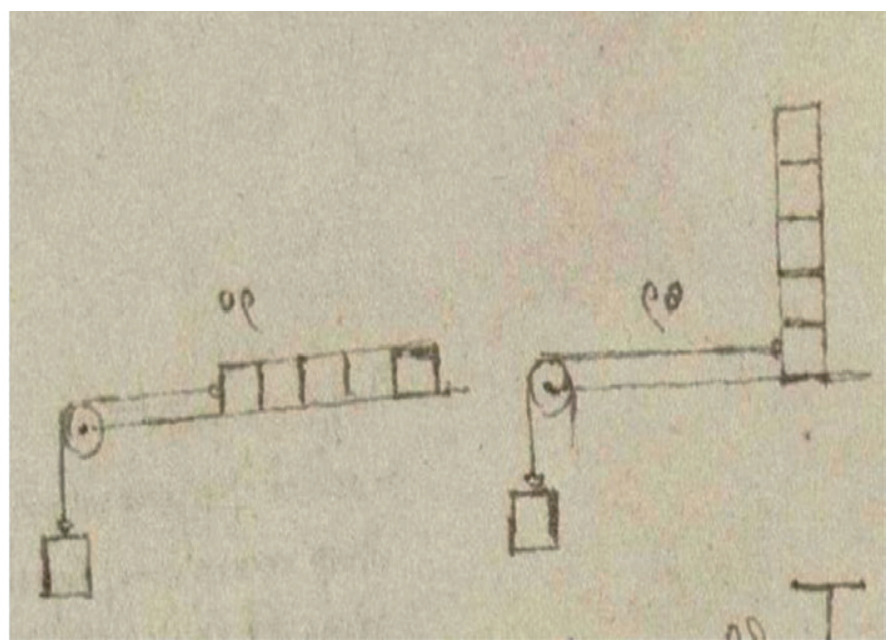

Fig. 4.

It is a matter of great delusion to me to see that Leonardo, who designed extraordinary machines to perform all sort of tasks, did not even try to design an experiment to measure the weight necessary to move an object at constant velocity on an horizontal plane. In that way he would have measured correctly the dynamical friction and as an added bonus he would have perhaps also understood the principle of inertia! In any case he arrives to the correct formulation of the laws of friction which he summarizes in the folio 187 of the atlantic code:

1. Quelli corpi che son di più pulita superficie hanno più facile confregazione.

2. Infra li corpi di ugual lubricità il piùgrave ha più potente resistenzia nella sua confregazione.

3. 'N un corpo d'ugual lubricità e di lati inequali la confregazione fatta da qualunche d'essi lati non muterà potenzia nel resistere al suo motore.

In the first he states that friction depends from the conditions of the two surfaces in contact. In the second he states that the frictional resistance depends on the weight of the body. In the third he states that the frictional resistance for the same weight is independent from the area of contact. The discovery of the laws of friction 200 years before Amonton stated the very same laws is a remarkable achievement. The 
fact that at that time Luca Pacioli, who taught algebra to Leonardo, did not use yet symbolic representation of known and unknown quantities prevented Leonardo from stating the second law as $\mathbf{F}_{A}=\mu \mathbf{N}$. However, as described in details by Hutching he uses in many applications values of the coefficient of friction $\mu$ which he must have determined from the ratio of frictional force $\mathbf{F}_{\mathbf{A}}$ to weight $\mathbf{N}$ although it is not clear if the coefficient refers to static or dynamic friction. It is true that Leonardo never records and describes quantitatively the results of his measurements but the judgment of C. Truesdell (The mechanics of Leonardo da Vinci, Springer, Berlin, 1968) who says that Leonardo never did any experiment in his life appears too harsh!

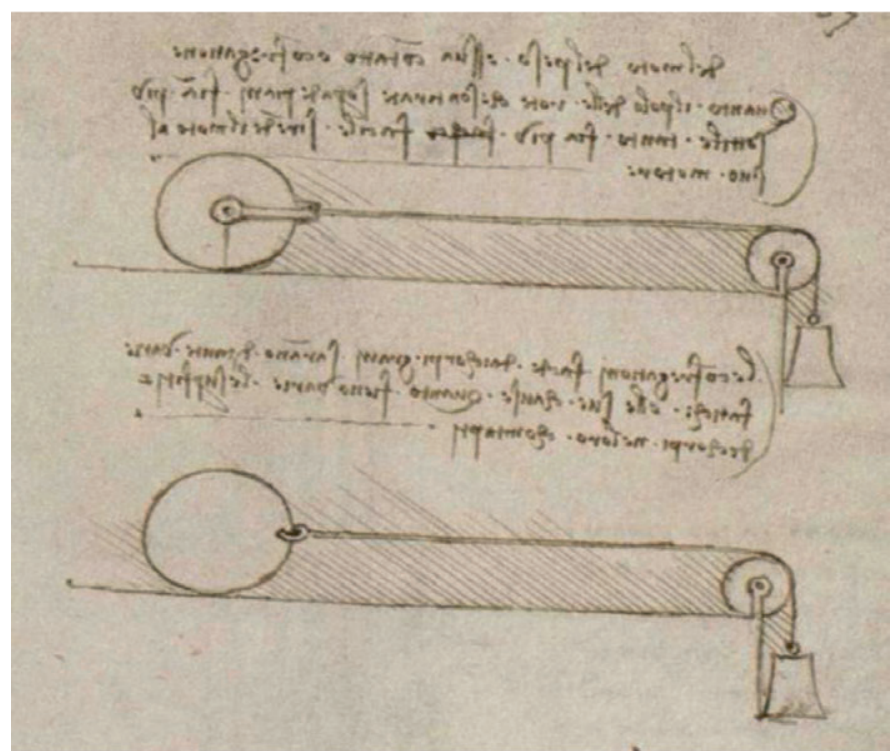

Fig. 5.

Leonardo is interested in applying the laws of friction to the study of the effort necessary to draw a cart on wheels such as the carriages which carry cannons and other materials on the battlefield. Thus first he tackles the problem of the difference between revolving friction and dragging friction. The drawing in Fig. 5, found in the Madrid code I65rc.14931497, is clearly designed for this purpose. Leonardo understand that the revolving friction is much smaller than the dragging one. He gives a very elaborate and obscure explanation of the revolving friction but he accom- 
panies it with a drawing which is self explanatory. In fact he shows that to move a wheel, even heavily loaded, it is sufficient a very small force enough to move the wheel from one equilibrium position to the next. As long as the wheel rolls the friction is static and much larger than the dragging friction. A great anticipation of the ABS (Assisted Braking System)!

In the Fig. 6 (drawing on the right) he indicates that a wheel loaded by a huge weight (900000) can be displaced by a tiny one $(1 / 900000)$. The numbers are purely indicative and in arbitrary units! Once more he is more at ease with drawing and geometry than with words and mathematics.

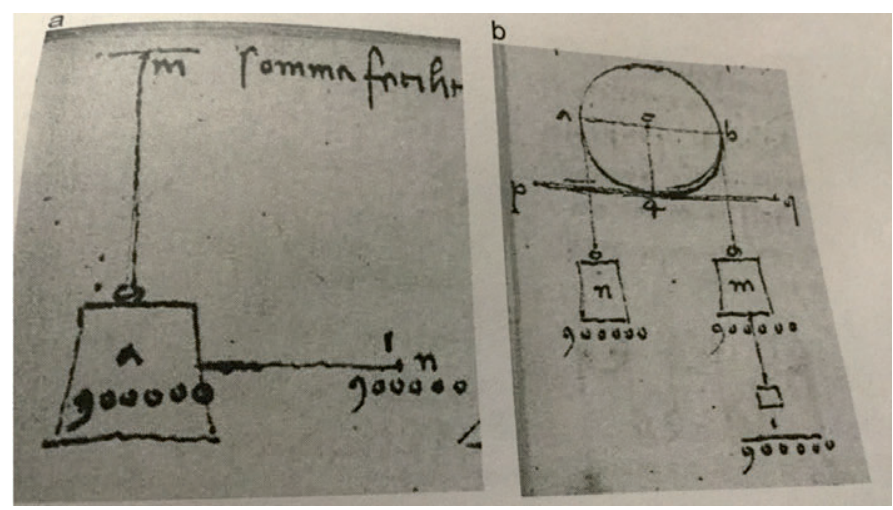

Fig. 6.

At this point Leonardo tries to understand where is the resistance to the movement of a wheel coming from. After several wrong attempts he understands correctly that the friction force acts on the axle of the wheel and that the crucial parameter is the circumference of the axle. The drawing shown in Fig. 7 (from the Atlantic Code 561r,c.1487-90) demonstrates that he planned experiments to understand the effect. There is no report of quantitative measurements but somehow he states that the friction is less if the circumference of the axle is smaller and he even arrives to the correct conclusion that the force necessary to draw a kart is the frictional force scaled by the ratio of the circumferences of the axle to the one of the wheel. By using the definition of work, the result follows immediately by equating, approximately, the active work to the passive one i.e. $\mathrm{F} . \mathrm{C}_{\mathrm{W}}=\mathrm{F}_{\mathrm{A}}$ $C_{A}$ from which $F=F_{A} \cdot C_{A} / C_{W}=F_{A} d_{A} / d_{W}$, where $C$ and $d$ are the circumference and the diameter of the wheel and the subscripts ${ }_{W}$ and ${ }_{\mathrm{A}}$ refer to 
the wheel and axle respectively. How Leonardo could arrive to the correct result without the concept of work, without symbolic algebra and even without any systematic and quantitative measurements is one more example of his extraordinary intuition which makes up for his mathematical shortcomings and his lack of quantitative experimentation.

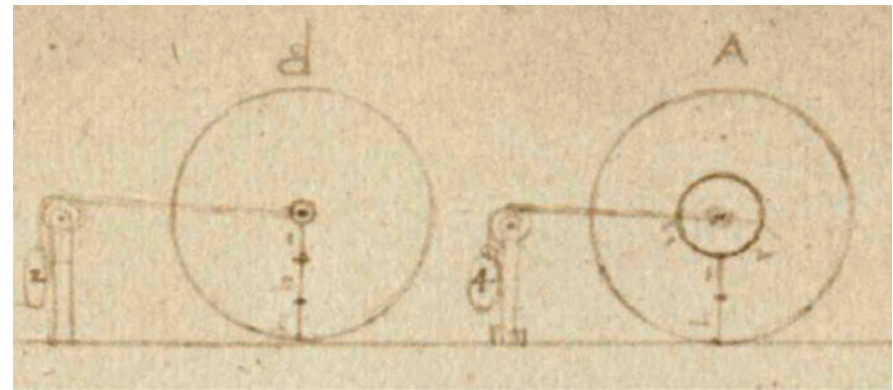

Fig. 7.

In the Madrid code (46r, c. 1503-5), he sets up a scheme to use his discoveries to find out the force necessary to move a given kart for any given load. This is a summary of what he does:

"He assumes a load of 96 pounds on a wheel having a circumference 24 times the one of the axle. He assumes a friction coefficient of 0.25 . Thus the frictional force is 24 pounds and the force to move the wheel is 1 pound. Now he can calculate the force necessary to move that particular wheel for any load. If, for example, the load is 6000 pounds the force necessary to move the wheel is 62.5 pounds. To arrive to this number he uses what at the time was called the "rule of three" which in symbolic algebra is the solution of the proportion 96:1 =6000:x."

The choice of those particular parameters for the wheel and the load make the calculations very simple. One assumes that Leonardo used the method also for more complicate numbers but he does not report any such example demonstrating his uneasiness with mathematics even when only multiplications and divisions are involved.

In the paper by Hutchings there are several more examples of applications of the laws of friction by Leonardo but the ones illustrated here are sufficient to draw conclusions about Leonardo's methods in his physical research:

1. With his drawings he proposes experiments which either he does not execute or, if he does, he does not report quantitative results. 
2. He arrives to the formulation of correct laws and conclusions with great intuition and imagination by using analogical more than deductive reasoning and with no use of mathematics.

3. He expresses his thinking better with drawing and geometry than with words and mathematics.

\section{FLUID DYNAMICS}

Leonardo investigated the laws of fluid dynamics mostly in connection with his extensive work in the field of hydraulic engineering. He came to a remarkable understanding of the equation of continuity and of the flow capacity for a stationary motion in a rigid pipe. He derived these concepts from the idea of the conservation of mass and understood that the flow is the product of the velocity times the section of the pipes. However, he never expressed these concepts in mathematical terms but he simply stated, correctly, that where the pipe (or river) is narrower the velocity is greater.

In the Leicester Code 6v he says:

"Ne fiumi di qualunque varieta di largeza e profondita a cha de per necessita che in ogni grado della sua lungheza con equal tempo passa equal quantita d' acqua». "In the rivers of whatever size and depth it is necessary that in any point of its path for the same time there is the same amount of water flowing"

In the Manoscript A, $57 \mathrm{r}$ he says:

"Il fiume d equale profondita sara tanto piufugha nella minore largheza che nella maggiore quancto la maggiore largheza avanza la minore..." "In a river of constant depth the flow will be faster in the regions of less width than in the wider ones by as much as the wider size is bigger than the smaller size..."

In the same folio he continues:

"...Esenplo. Verbigratia se fiaun loco che abbi 3 varie largheze ......" where he describes in a poetic way the analogy of the flow of water in a river with the flow of a crowd of people in a street of variable width whereby he points out that where the street narrows people are forced to walk faster to keep up with the flow of the crowd. 
Leonardo was intrigued by the problem of the velocity with which a liquid spurts from a hole or an opening in a container as a function of the depth of the hole from the free surface of the liquid. This is the problem solved by Torricelli which goes under the name of Torricelli Theorem. The interest of Leonardo for Torricelli Theorem is twofold. On one hand the problem is important when bottling the wine from a barrel and Leonardo did produce wine for a short time in his life when he was given by the duke Ludovico il Moro as a gift a piece of land close to the church of Santa Maria delle Grazie (the vigna di Leonardo has been recently restored in the same place and with the same kind of grapes and is open to the public to be visited). The other application is to the measurement of the amount of water drawn from a gate in the irrigation channels. In the following I will show how Leonardo tackled these problems.

Regarding the problem of bottling the wine he says in the Manuscript I 7r:

“...se una botte ha in se il vino alto 4 braccia e gitta il vino lontano da se 4 braccia, quando il vino sarà nel calare disceso all'altezza di 2 braccia della botte gitterà ella il vino per la medesima cannella ancora 4 braccia? Cioè se il calo e l'empito del gittare della cannella diminuisce con equale proporzione o no..." "if a barrel contains wine up to 4 "braccia" (a unit of the order of a yard) and gushes the wine 4 "braccia" away, when the wine in the barrel is lowered to a level of 2 "braccia" will the wine gush still 4 "braccia" away ? In other words if the level of the wine and the speed of exit from the hole decrease in equal proportion or not...."

Clearly Leonardo does not have the answer so, as he does in many other instances, he poses the problem in the form of a question. Actually the range reached by the wine spurting from the hole depends from the initial velocity and the level of the hole from the ground. This is illustrated in the Fig. 8 based on the current knowledge of Torricelli's Theorem and parabolic motion.

From what Leonardo says it appears that the barrel is set 1 "braccia" from the ground although he does not says it. In fact for $\mathrm{H}=1$ and $\mathrm{h}=4$ the range or throw $\mathrm{G}$ is also 4 "braccia". Of course Leonardo did not know the laws of parabolic motion of a mass in the gravitational field. However, he seems to understand that for a constant height from ground the range $G$ is proportional to the initial horizontal velocity. 


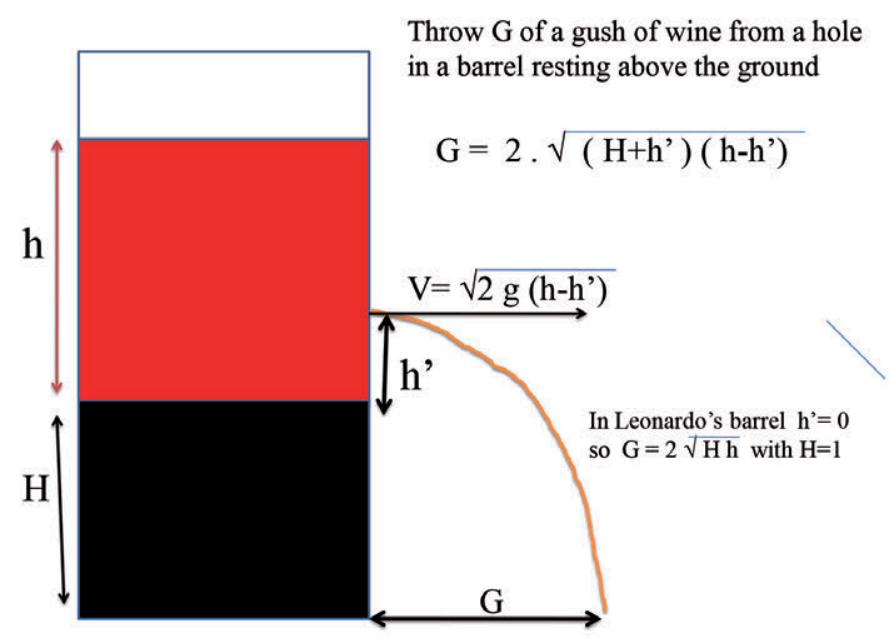

Fig. 8.

Thus he has a way to experiment the velocity (which he calls empito) as a function of the level of the wine above the hole. What clearly sets him off is that the velocity is not proportional to the level $\mathrm{h}$ but to the square root of $\mathrm{h}$. I am convinced that he did try to answer to the question that he poses above but got confused by the fact that the throw $G$ when the level decreases from 4 to 2 "braccia" does not decrease from 4 to 2 but from 4 to $2 \sqrt{2}$. If he had known the square root (which he should have) and he had used symbolic algebra (which he could not at his time) he would have discovered Torricelli's law!!

His experimentation is described in the drawing from the Madrid Code 1, 124r (Fig. 9).

More experiments are described in the Atlantic Code 219r (Fig. 10).

The trajectory of the water spurting from holes at different levels are only qualitatively correct (Fig. 10). As usual Leonardo does not reports any quantitative and systematic measurements. In some cases the drawings are also incorrect. Thus we can conclude that Leonardo understood that the speed with which the water spurts from a hole in a barrel is higher when the level of the water above the hole is higher but he does not go any further and he does not seem to relate the effect to hydrostatic pressure (a concept familiar to him from Archimedes work). 


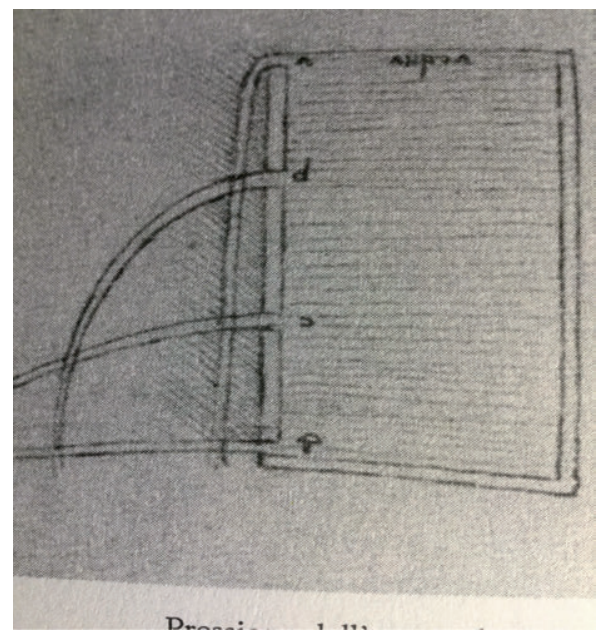

Fig. 9.

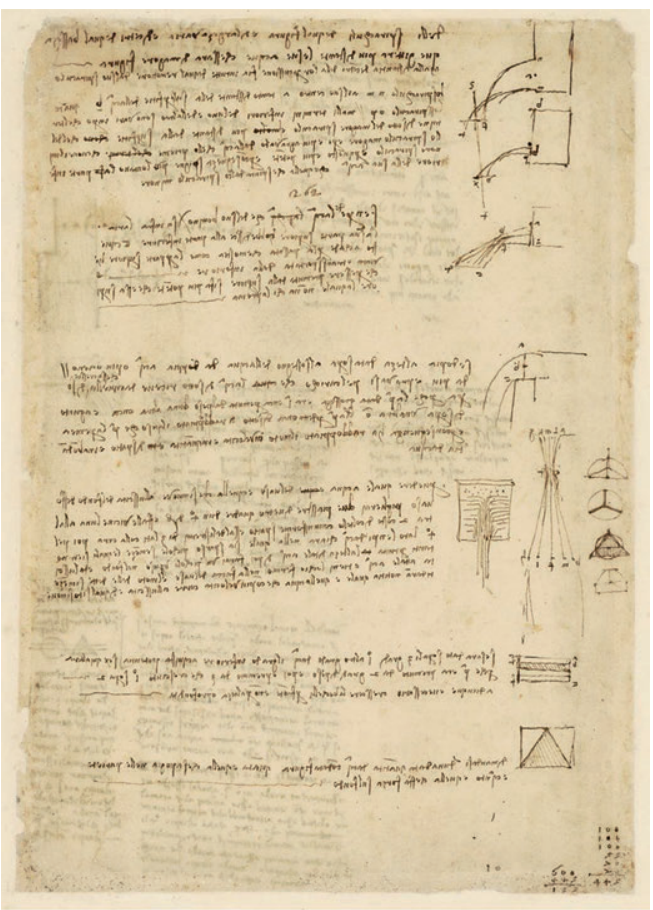

Fig. 10. 
Leonardo did not miss to realize that the spout of water out of a container due to hydrostatic pressure afforded an easy way to investigate parabolic motion. He could not understand parabolic motion without the knowledge of Newtons's laws but he could study it and describe it in a phenomenological way. This problem was important to him to understand and design the throw of cannon balls. A device he used for the purpose is described in the drawing below (Fig. 11). It is a clever device made up of a pressurized rubber container where he applied spigots that he could orient in different ways to simulate all kind of trajectories.

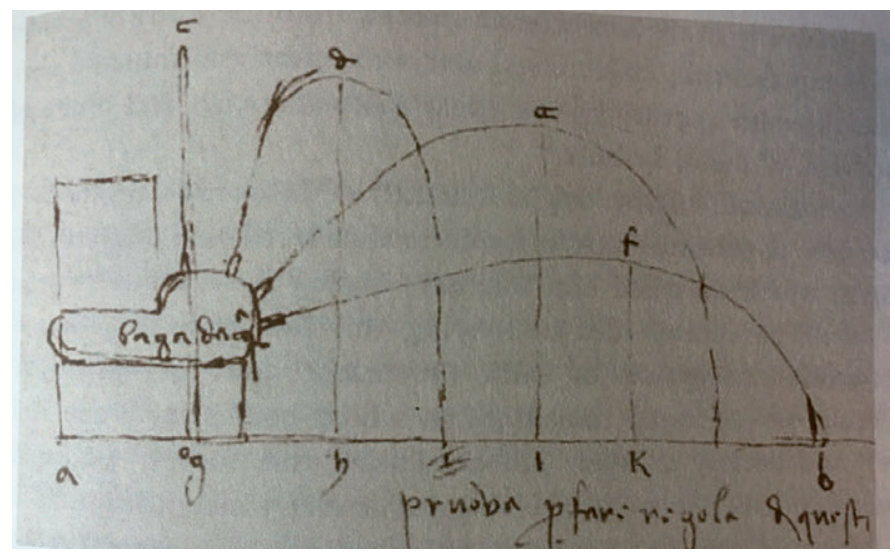

Fig. 11.

His insatiable curiosity pushed him to investigate even more complicate situations like the one described in the drawing below (Fig. 12).

A translation of Leonardo's words would not do justice to this remarkable text. What he describes is that when more jets of water with different horizontal velocity merge the range of the throw of the combined jet is intermediate between the ranges of the individual jets. This is the result of the composition of parabolic motion as the combination of horizontal and vertical motion, the conservation of momentum and the different flow from the different holes. He did not have any idea of these concepts (except for the flow) but he did arrive to a qualitative correct result. Did he arrive to this by experimenting or by reasoning? As always with Leonardo it is difficult to answer the question since he does not report the results of his experimentation granted that he performs it. 


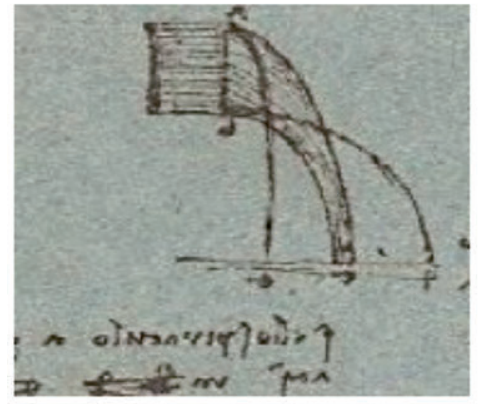

Codice Atlantico Folio 256 r, Biblioteca Ambrosiana
Leonardo writes:»Se lo spiraculo a gitta la sua acqua in e e lo spiraculo $b$ la gitta in d seguira che se li due spiraculi saran contiunati per tutto lo spazio ab, che tuttal acqua di tale spiraculo si gittera in c. E questo accade perché la parte che prima andava dal $b$ in $d$ è poi aggravata dal peso ab che la piega in $c e$ l acqua ae che prima cadeva in e, e poi sostenuta dal moto ab.»

Fig. 12.

Related to hydrostatic pressure are also Pascal principle and the principle of communicating vessels which were known by the Hellenistic scientists. Leonardo understood both but, as demonstrated by what he says, he draws his conclusions from observation rather than experimentation:

“......il mare è la più bassa parte del mondo: nessuna superficie d'acqua può per sua natura essere più bassa che quella del mare. La spera dell'acqua desidera perfetta rotondità e quella parte che supera la sua universal superficie non può durare e con breve tempo si spiana" "... the sea is the lowest part of the world: no water surface can by its nature be lower than the one of the sea. The sphere of the water desires perfect roundness and the portion that surmounts its universal surface cannot last and in a short time makes level"

Leonardo's incomplete understanding of Torricelli Theorem does not prevent him from providing the duke Ludovico il Moro a great service in correcting the way water flow was measured. In fact at that time the unit, "oncia", utilized to measure the amount of water dispensed by the irrigation channels was based on the surface of the gate to be open and the time duration of the irrigation. The exit speed of the water was not 
taken into account. Leonardo realized that the speed depends on the level of the gate with respect to the level of the water in the channel (as from Torricelli 's law) and thus proposed a change in the definition of the "oncia" to take into account the effect. He did not build himself any device to monitor the flow but the ones built at his time and improved in later centuries are based on Leonardo' observation.

Even in this case one can see that Leonardo was not interested in arriving to a complete and correct statement of the physical laws. Once he had understood enough to solve his practical problems he would be satisfied!

In the Atlantic Code, folio $831 \mathrm{r}$ (Fig. 13), it is depicted the system to dispense water in the Navijlio di san crisstofano dj mjlano facto addi 3 di maggio 1509.

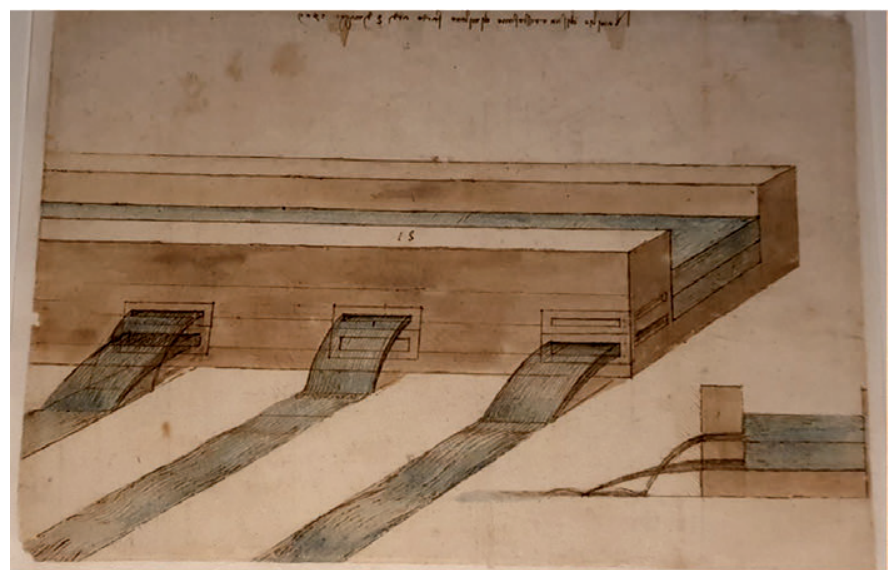

Fig. 13.

\section{CONCLUSIONS}

Leonardo, although he enunciates correctly the principles on which the modern experimental scientific method is based, does not seem to implement them and thus we cannot say that he anticipated the scientific revolution of Galileo. Part of the problem is his limited understanding of mathematics. Of course many necessary mathematical tools were not available at his time,like symbolic algebra or calculus, but even the tools available were not very familiar to him even after the teachings 
of his friend Luca Pacioli. But the main problem is that he uses the experimentation in a limited way. In fact he often draws experiments but he then fails to follow up with the implementation of his drawings and he never gives quantitative results for the experiments granted that he did perform them at all. Furthermore the reasoning that follows up his experimentation is more often analogical than inductive.

He did much better with geometry which is more directly related to his extraordinary ability as an artist and this explains why he was very successful as a descriptive scientist in areas such as anatomy, engineering, geology, botany, cartography. As a visual scientist he is very successful because of his insatiable curiosity and immense capacity in observing nature and phenomena and in describing them with his drawings. In this way he arrives often to incredible intuitions. But an experimental science like physics requires to set up specific experiments to interrogate nature and in this way to materialize the intuitions and this is not generally done by Leonardo.

The great scientific merit of Leonardo is the one of having helped to rediscover the great knowledge of the Hellenistic world and at the same time to having pointed out the necessity to check with its own experience the validity of the previous knowledge without fear of rejecting what appeared to be incorrect. In this respect he stands, as analyzed so well by Luigi Borzacchini, a solitary giant connecting the old scientific world and to the new.

\section{AKNOWLEDGEMENTS}

I would like to thank A. Rigamonti and P. Mazzarello for stimulating discussions. 


\section{REFERENCES}

Reference to articles and books dealing specifically with the physics of Leonardo are given in the text. We list below some general references which were consulted in writing this note.

Jean Paul Richter, The notebooks of Leonardo da Vinci, Dover Publications (1970) original publication 1883.

Luca Beltrami, Scritti di Leonardo, Istituto Editoriale Italiano (1920).

Carlo Pedretti, Leonardo da Vinci, Giunti Gruppo Editoriale, (2000).

Michael White, "Leonardo: the first scientist", St. Martin Press, New York (2000).

Augusto Marinoni, Trascrizioni codice atlantico Vol 1 ,2, 3 .

Paolo Galluzzi, Mostre, Conferenze, Interviste, Articoli, Internet.

Domenico Laurenza, Enciclopedia Treccani, ottava appendice, 2013.

Charles Nicholl, Leonardo da Vinci: Flights of the mind, Penguing books, 2004.

Stefan Klein, L'eredità di Leonardo, Bollati Boringhieri, 2017 (2005).

Mario De Micheli, Leonardo da Vinci, l'uomo e la natura, Feltrinelli (1991).

Walter Isaacson, Leonardo da Vinci, Simon and Schuster, 2017.

Carlo Vecce, Leonardo, Salerno editrice (2005).

Edoardo Zanon, Codex on flight, Leonardo 3 srl, (2000).

Giovanni Giovannetti, Indagine su Leonardo, Effigie (2015). 
